\title{
Terminal Half Life
}

National Cancer Institute

\section{Source}

National Cancer Institute. Terminal Half Life. NCI Thesaurus. Code C85818.

The time required for $50 \%$ of a drug to be excreted from a body tissue. 